\title{
Update on the management of diabetic polyneuropathies
}

This article was published in the following Dove Press journal:

Diabetes, Metabolic Syndrome and Obesity:Targets and Therapy 20 July 2011

Number of times this article has been viewed

\author{
Jayadave Shakher' \\ Martin J Stevens ${ }^{1,2}$ \\ 'Heart of England NHS Foundation \\ Trust, Birmingham, UK; ${ }^{2}$ School \\ of Clinical and Experimental \\ Medicine, University of Birmingham, \\ Birmingham, UK
}

\begin{abstract}
The prevalence of diabetic polyneuropathy (DPN) can approach 50\% in subjects with longer-duration diabetes. The most common neuropathies are generalized symmetrical chronic sensorimotor polyneuropathy and autonomic neuropathy. It is important to recognize that $50 \%$ of subjects with DPN may have no symptoms and only careful clinical examination may reveal the diagnosis. DPN, especially painful diabetic peripheral neuropathy, is associated with poor quality of life. Although there is a better understanding of the pathophysiology of DPN and the mechanisms of pain, treatment remains challenging and is limited by variable efficacy and side effects of therapies. Intensification of glycemic control remains the cornerstone for the prevention or delay of DPN but optimization of other traditional cardiovascular risk factors may also be of benefit. The management of DPN relies on its early recognition and needs to be individually based on comorbidities and tolerability to medications. To date, most pharmacological strategies focus upon symptom control. In the management of pain, tricyclic antidepressants, selective serotonin noradrenaline reuptake inhibitors, and anticonvulsants alone or in combination are current first-line therapies followed by use of opiates. Topical agents may offer symptomatic relief in some patients. Disease-modifying agents are still in development and to date, antioxidant $\alpha$-lipoic acid has shown the most promising effect. Further development and testing of therapies based upon improved understanding of the complex pathophysiology of this common and disabling complication is urgently required.
\end{abstract}

Keywords: diabetes, neuropathic pain, microvascular, glucose

\section{Introduction}

Diabetes is the most common cause of neuropathy leading to significant morbidity and is associated with increased mortality. ${ }^{1}$ Prevalence approaches $50 \%$ for people with long-established diabetes. Presentation, in the early stages, can comprise symmetrical, painful neuropathy involving the lower limbs, which can predate the diagnosis of diabetes. Paradoxically in later stages, pain can still be present with disabling symptoms, yet on clinical examination there is loss of sensation, so-called "painful painless neuropathy". Poor glycemic control leads to progression of DPN and many studies have shown that intensification of metabolic control can slow or halt disease progression. Currently available disease-modifying treatments have not been effective in reversing the pathological process and present therapies are targeted, therefore, more towards pain relief.

\section{Definition}

DPN is defined as the presence of symptoms and/or signs in the peripheral nerves, predominantly affecting the lower extremities in the absence of other causes of neuropathy. 
The San Antonio Consensus Statement on Diabetic Neuropathy defined the condition as being a "demonstrable disorder, either clinically evident or subclinical in the setting of diabetes without other causes of peripheral neuropathy". ${ }^{2}$

\section{Epidemiology}

The epidemiology and the natural history of DPN are difficult to define, reflecting the inconsistencies of clinical diagnostic criteria, variable selection of patients, and wide-ranging physiological techniques. The EURODIAB Complications Study identified a prevalence of $28 \%$ for DPN at baseline, with glycemic control and duration of diabetes being major determinants; similar findings were observed in subjects in the Diabetes Control and Complications Trial (DCCT). ${ }^{2}$ In a cohort of 4400 Belgian patients, the prevalence was estimated to be about $7.5 \%$ in newly diagnosed diabetes, increasing to $45 \%$ after 25 years of diabetes. ${ }^{3}$ In the United Kingdom, the prevalence of DPN among a hospital clinic population was around $29 \%{ }^{4}$ The prevalence is estimated to be $10 \%$ to $18 \%$ in newly diagnosed type 2 diabetes based on nerve electrophysiological studies, reflecting that "mild" disturbances of the glucose milieu can lead to nerve damage. ${ }^{5}$ The enhanced sensitivity of nerves to glucotoxicity is supported by the presence of symptomatic neuropathies in individuals who were found to have impaired glucose tolerance (IGT) which typically affects small nerve fibers based on measurements of intra-epidermal nerve fiber density (IENFD). ${ }^{6}$ In the Augsburg surveys, the prevalence of DPN based on Michigan Neuropathy Screening Instrument was $13.0 \%$ in those with IGT, $11.3 \%$ in those with impaired fasting glucose (IFG), and $7.4 \%$ in those with normal glucose tolerance (NGT) vs $28.0 \%$ in subjects with established diabetes $(P=0.05$ for diabetes vs NGT, IFG, and IGT). ${ }^{7}$

The reported prevalence of painful DPN typically ranges from $10 \%-26 \%$ based on differing criteria used to diagnose neuropathic pain. ${ }^{8}$ In a European multicenter study of 1171 diabetic patients, the prevalence of painful DPN in subjects with type 1 and type 2 diabetes was $11.6 \%$ vs $32.1 \%$ respectively in the lower limbs and $7.1 \%$ vs $16.6 \%$ in the upper limbs. In newly diagnosed type 2 subjects, the prevalence has been reported to be $6 \%$ increasing to $20 \%$ at 10 years. ${ }^{9}$

\section{Risk factors for DPN and neuropathic pain}

The risk factors for the development of DPN were analyzed in the EURODIAB Prospective Complications Study of 1100 people with type 1 diabetes followed over a period of 7.3 years. Risk factors appeared to be similar to the factors for macrovascular disease, such as hypertension, smoking, elevated $\mathrm{HbA}_{1 \mathrm{c}}$, increased lipid levels, duration of diabetes, and body mass index (Figure 1). ${ }^{10}$ In the Augsburg surveys, age, waist circumference, and diabetes were shown to be independent risk factors for the developing neuropathic pain. The presence of peripheral arterial disease was a significant contributor to neuropathic pain both in diabetic and nondiabetic subjects. This is an important factor to be considered in the diagnosis and treatment of neuropathic pain. ${ }^{11}$

\section{Symptoms and signs}

The classification of diabetic neuropathies is complex reflecting the diverse etiology, pathology, the heterogeneous nature of symptoms, varied clinical course, and pattern of neurological involvement (Table 1). DPN can be broadly divided as suggested by Thomas et $\mathrm{al}^{12,13}$ and Boulton et al ${ }^{14,15}$ into generalized polyneuropathies and focal and multifocal varieties. Recently the Toronto Diabetic Neuropathy Expert Group suggested a further division of the generalized varieties into two subgroups of typical and atypical reflecting differences of onset, course, clinical manifestations, associations, and pathophysiology. ${ }^{16}$ Furthermore, minimal criteria were suggested for typical DPN (into categories of possible, probable, confirmed, and subclinical) based upon abnormalities of symptoms and signs and nerve electrophysiology. According to these criteria, the presence of an abnormality of nerve conduction in addition to a symptom(s) or a sign(s) is necessary for confirmation. However in the presence of normal electrophysiology, a validated measure of small fiber neuropathy (Figure 2) could be utilized. ${ }^{16}$

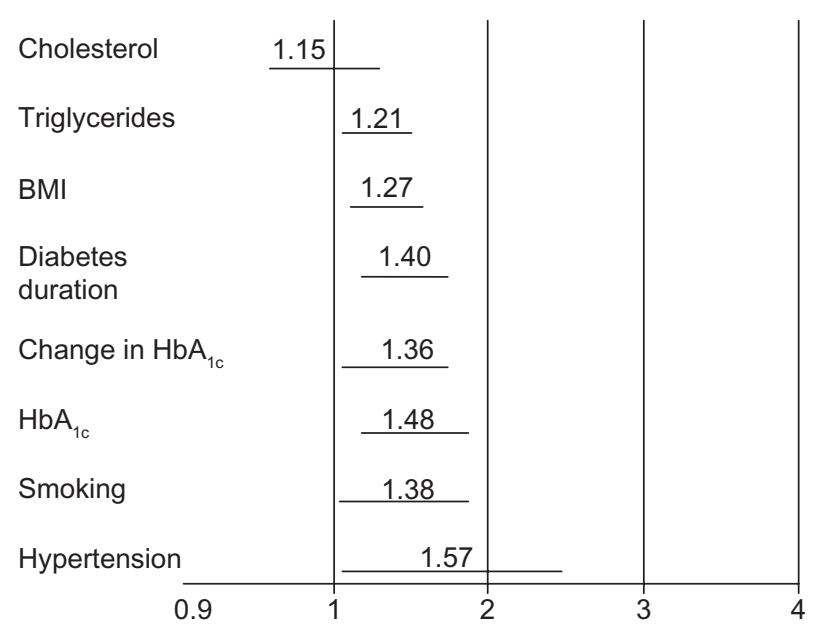

Figure I EURODIAB: risk factors for incidence of polyneuropathy.

Notes: Excluding cardiovascular disease and retinopathy. Odds ratios $(95 \% \mathrm{Cl})$; $\mathrm{n}=1 \mathrm{I} 0 \mathrm{I}$ with type 2 diabetes; follow up $7.3 \pm 0.6$ years. 
Table I Classification of diabetic polyneuropathies

A. Generalized symmetrical polyneuropathy
- Chronic sensorimotor polyneuropathy
$\diamond$ Small fiber neuropathy
$\diamond$ Large fiber neuropathy
$\diamond$ Mixed
- Acute sensory neuropathy
$\diamond$ Hyperglycemic neuropathy
$\diamond$ "Cachetic" neuropathy
- "Peripheral"autonomic neuropathy
$\diamond$ Sudomotor neuropathy
$\diamond$ "Autosympathectomy"
B. Focal neuropathy
- Cranial neuropathy
- Focal-limb neuropathy
C. Multifocal neuropathies
- Radiculoplexus neuropathies
$\diamond$ Lumbar polyradiculopathy (diabetic amyotrophy)
$\diamond$ Lumbo-sacral polyradiculopathy
$\diamond$ Thoracic polyradiculopathy

\section{Generalized polyneuropathy Diabetic sensorimotor polyneuropathy}

Diabetic sensorimotor polyneuropathy (DSPN) is perhaps the most common form of DPN. It is a chronic, symmetrical neuropathy, which typically begins in the toes and gradually and insidiously ascends to involve the lower legs. Lesions or dysfunction of small myelinated and unmyelinated nerve fibers and larger myelinated nerve fibers occur in varying combinations; however, in most cases, the earliest deficits involve small nerve fibers. The features of small fiber neuropathy can include paresthesias and dyesthesia, hyperalgesia, burning, or lancinating pain and deficits in pain and temperature perception. Sensory symptoms can be mild; occasional tingling or pins and needles (paresthesia) or more disabling in terms of burning or stabbing with symptoms tending to be worse at night. The most frequent location of pain has been reported to be as follows: $96 \%$ feet, $69 \%$ balls of feet, $67 \%$ toes, $54 \%$ dorsum of foot, $39 \%$ hands, $37 \%$ plantum of foot, $37 \%$ calves, and $32 \%$ heels. ${ }^{17}$ In extreme cases, patients may experience hypoalgesia and allodynia when even the lightest of touch can provoke perception of severe pain. The precise prevalence of allodynia in DPN is however controversial. Unpleasant sensations of lancinating or "electric-shock" nature can result from small fiber involvement. Negative symptoms of numbness and hypoalgesia are also commonly reported within the presentation of sensorimotor polyneuropathy. Large myelinated fiber involvement leads to loss of vibration, touch, and position perception with decreased or absent ankle reflexes. Severe impairment of proprioception can lead to sensory ataxia and denervation-mediated wasting of small intrinsic muscles of the feet and hands, which can lead to weakness and deformity and occurs late in the disease process. ${ }^{12,18-21}$ The duration of pain varies with complete to partial remission possible if a precipitating event can be identified. ${ }^{22}$ Shorter pain duration (ie, $<6$ months), in general, has a better prognosis.

It is generally proposed that chronic hyperglycemia with resultant downstream metabolic derangements in concert with cardiovascular risk factors ${ }^{23}$ leads to impaired microvascular perfusion which is the fundamental deficit in pathogenesis of DSPN and is often found in association with other long-term microvascular complications. ${ }^{16,23}$

\section{Acute sensory neuropathy}

Rarely, the symptoms of DPN are acute with severe intensity of pain associated with sudden and extreme weight loss. This has been associated with depression and erectile dysfunction. Electrophysiological evidence of neuropathy may be mild or absent consistent with predominant involvement of small nerve fibers. Symptoms may subside in $<1$ year and weight loss responds well to insulin therapy. ${ }^{24}$ Similar findings may be observed in girls with anorexia and diabetes, ${ }^{24}$ which can portend a troublesome future of rapidly progressive DPN.

Similarly, the so-called rapidly reversible hyperglycemic neuropathy, which occurs in patients with recently diagnosed or poorly controlled diabetes, usually presents with distal sensory symptoms that are unlikely to be associated with structural nerve abnormalities and recover following restoration of euglycemia. ${ }^{16}$

Acute painful neuropathy which develops after improvement of glycemic control, so-called "insulin neuritis", has been described as "non-length-dependent" in that the distal extremities are not necessarily the most severely affected..$^{25,26}$ This topographic distribution of neuropathy has also been described in subjects with impaired glucose tolerance. ${ }^{27}$ Symptoms usually respond to conventional treatments for neuropathic pain within 1 year.

\section{Autonomic polyneuropathies}

In diabetic neuropathy, innervation of peripheral vasculature is decreased or absent. Loss of sympathetic tone in the blood vessels results in vasodilation leading to arteriovenous shunting. The "warm" neuropathic feet due to arteriovenous shunting can be associated with the distension of foot veins that fail to collapse even when the foot is elevated and can result in edema, which is resistant to diuretics. The 
increased blood flow in the feet has been postulated to cause osteopenia and is associated with the development of Charcot neuroathropathy. ${ }^{28}$ The oxygen tension of the blood in these veins is typically raised.

Peripheral sudomotor neuropathy can affect the feet with loss of sweating, resulting in dry skin with fissures predisposing to the risk of infection. ${ }^{29}$ The term "autosympathectomy" has been used to describe the occurrence of peripheral vasomotor instability and peripheral sudomotor neuropathy. Sweat glands are innervated by sudomotor, postganglionic, thin, unmyelinated cholinergic sympathetic C-fibers. C-fibers also contribute to microvascular blood flow regulation. C-fiber dysfunction can occur early in the course of DPN.

Several methods have been developed to assess sudomotor function with variable degree of complexity and accuracy including thermoregulatory sweat testing, quantitative sudomotor axon reflex test sympathetic skin response, and quantitative direct and indirect axon reflex testing, silicone impressions, and the indicator plaster. The indicator plaster has been developed as a simple tool to detect the presence of DPN. ${ }^{30}$

Measurement of IENFD is also becoming widely accepted as an important highly reproducible ${ }^{31,32}$ tool for the quantitative assessment of the presence and severity of small sensory fiber loss. Intra-epidermal nerve fibers are the most distal processes of small myelinated and unmyelinated axons. These fibers can be quantified utilizing a minimally invasive technique of skin punch biopsy ${ }^{31}$ (Figure 2). Normative ranges have been reported ${ }^{31}$ which demonstrate that the density of epidermal nerve fibers decreases with age and is lower in men than in women. ${ }^{32}$ IENFD has been found to correlate with the severity of neuropathy ${ }^{34,35}$ as measured using sural nerve small myelinated fiber density, ${ }^{35}$ thermal thresholds, ${ }^{33,36,37}$ vibration perception threshold, and electrophysiology. ${ }^{33,36}$
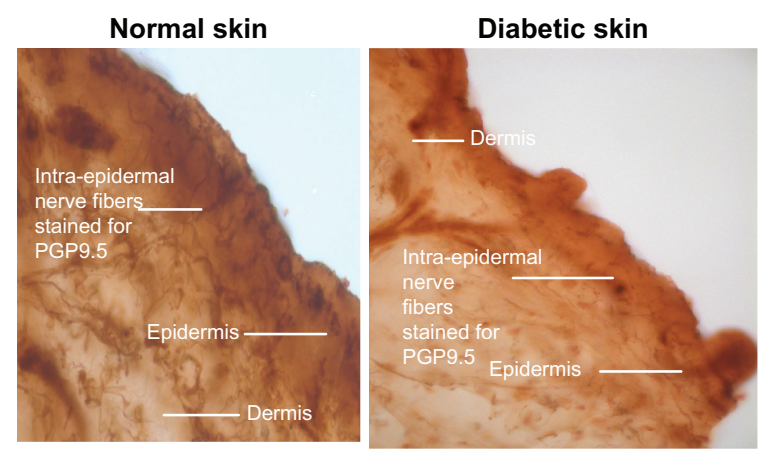

Figure 2 PGP 9.5 staining in nerves.
Small sensory nerve fiber loss in the cornea can also be assessed using the technique of corneal confocal microscopy. ${ }^{16,33}$ This technique has been shown to correlate with loss of IENFs and with the severity of neuropathy in patients with diabetes. ${ }^{33}$ It appears to be a highly sensitive measure by which to measure a therapeutic effect of disease-modifying interventions since it was reported to improve 6 months following pancreatic and kidney transplantation. ${ }^{38}$

\section{Focal and multifocal neuropathies}

Different mechanisms such as mild, repeated mechanical trauma, compression and entrapment, ischemia, and inflammatory process have been invoked in the development of focal and multifocal neuropathies, ${ }^{39-41}$ which differ from typical DSPN in that they may occur early as well as later in the course of diabetes.

Mononeuropathy is common in both type 2 and type 1 diabetes. Cranial neuropathy, which perhaps results from inflammation, microvasculitis, and/or ischemia is rare and commonly affects the nerves that supply the extraocular muscles, especially oculomotor, abducens, and trochlear. Patients with diabetic opthalmoplegia present with unilateral pain, ptosis, and diplopia with sparing of pupillary reaction. Though these neuropathies are similar to those observed in nondiabetic subjects, Bell's palsy occurs more frequently in diabetic than nondiabetic patients. Mechanical insult is likely to contribute to carpal tunnel syndrome which results from median nerve entrapment at the wrist (median mononeuropathy) or foot drop secondary to peroneal nerve involvement at the fibular head. Median mononeuropathy can be asymptomatic and can lead onto wasting and weakness of hand grip..$^{42}$

\section{Radiculo-plexus neuropathies}

Lumbosacral plexus-radiculo-neuropathy involve the L2, L3, and $\mathrm{L} 4$ roots and is often described as diabetic amyotrophy. ${ }^{16}$ Typically, older patients in the fifth to sixth decades of life with type 2 diabetes present with thigh pain followed by muscle weakness in one leg and sensory loss at the level of the lumbar plexus or lumbar roots and femoral nerve. The knee jerk reflex is usually reduced or absent on the affected side with preservation of ankle jerk unless affected by distal polyneuropathy. The symptoms may have monophasic or stepwise progression and are usually accompanied by weight loss. The condition tends to resolve over 6 months to 1 year. The diagnosis is made on history and clinical examination and electromyographic studies. The etiology may be an 
immune mediated vasculitis with ischemia since there is evidence of immune complex and complement deposition in nerve and muscle biopsy. Limited data suggest that treatment with intravenous immunoglobulins, prednisolone, and/or plasma exchange may result in fewer long-term neurological sequelae. ${ }^{43-45}$ It is important to achieve good metabolic control in all cases.

Diabetic truncal radiculoneuropathy tends to affect middle-aged to elderly male patients. It is less common than lumbosacral plexus-radiculo-neuropathy but causes marked symptoms with a girdle-like distribution pain over the lower thoracic or abdominal wall. It may be uni- or bilaterally distributed and resolution generally occurs within 4-6 months.

\section{Pathophysiology}

The development of DPN is multifactorial. The metabolic effects of chronic hyperglycemia and the consequences of ischemia on the peripheral nerves are likely to be the two fundamental mechanisms leading to neuro-axonal dysfunction and damage.

In sensorimotor polyneuropathy, the pathophysiological effects of hyperglycemia are wide ranging and include activation of polyol pathway, generation of reactive oxygen species (ROS) (oxidative stress) and reactive nitrogen species (nitrosative stress), and accumulation of advanced glycation end products (AGE) ${ }^{46}$ (Figure 3 ). Excess glucose flux through the polyol or sorbitol pathway is reduced to sorbitol by the enzyme aldose reductase, a rate limiting step in this pathway, before being oxidized by sorbitol dehydrogenase to fructose, a potent glycating agent. The intracellular accumulation of sorbitol leads to reduction in nerve myoinositol and taurine and disruption of $\mathrm{Na}^{+} / \mathrm{K}^{+}$-ATPase membrane activity, leading to nerve sodium accumulation, impaired axonal transport and structural damage to the nerves.

Hyperglycemia accelerates the glycation of free amino group on proteins, lipids, and nucleic acids with alteration in their molecular structure and functions. ${ }^{47}$ The basement membrane of endothelial cells becomes glycosylated thereby contributing to impaired vasodilation. There is also excess formation and accumulation of AGEs due to reduced clearance of these macromolecules. Additionally, AGEs bind to receptors of AGE on macrophages with production of inflammatory cytokines (interleukin-1, tumor necrosis factor- $\alpha$ ), growth factors (insulin like growth factor, platelet derived growth factor, tissue growth factor- $\beta$ ) and adhesion molecules (vascular cell adhesion molecules-1) (VCAM-1). ${ }^{48-54}$
Elevated intracellular glucose also stimulates formation of diacylglycerol, which leads to the activation of protein kinase $\mathrm{C}$ (PKC). ${ }^{53,54}$ The role of PKC is better defined in the pathogenesis of diabetic retinopathy and although the mechanism of its involvement in neuronal damage is unclear and debated, it probably is mediated via an effect on endothelial cell function.

A common final endpoint for many pathogenic pathways is impaired nerve perfusion, hypoxia, and nerve energetic defects. The multiple mechanisms cited above can result in overproduction of ROS, especially superoxide anion by the mitochondrial electron transport chain. The availability of endothelial nitric oxide (NO) is reduced as superoxide binds to NO to form the strong oxidant peroxynitrite which is directly toxic to endothelial cells. ${ }^{56-59}$ Endothelial cells elaborate NO, a potent vasodilator, which antagonizes thrombosis, has anti-inflammatory properties, is important in cell signaling, and can inhibit growth of vascular smooth muscle cells. ${ }^{56-62} \mathrm{NO}$ also inhibits the production of the potent vasoconstrictor peptide endothelin (ET)-1. Other agents involved in mediating the vasodilatation of microcirculation include substance $\mathrm{P}$ and calcitonin gene related peptide (CGRP), in addition to bradykinin, histamine, and vasoactive intestinal polypeptide there is impaired dilator response to these peptides in diabetes. ${ }^{55-58}$ Therefore, diabetes results in an imbalance of vasoactive agents, with the ultimate effect of impaired microvascular perfusion.

Another novel pathway, which has been implicated in the pathogenesis of the complications of diabetes, is activation of nuclear enzyme poly (ADP ribose) polymerase (PARP). Increased oxidative stress results in DNA damage and PARP 1 activation, which can lead to cellular energy failure, which is thought to be important in the pathogenesis of DPN. ${ }^{63}$ Diabetic rodent models administered PARP inhibitors or deficient in the PARP gene demonstrate protection against the development of experimental DPN. These models also demonstrate reduced levels of epineurial vessel superoxide and nitrotyrosine, suggesting that the relationship between oxidative stress and PARP may be bidirectional rather than unidirectional. ${ }^{63}$ For a detailed review of the role of oxidative stress in the pathogenesis of DPN, the reader is referred to Figueroa-Romero et al. ${ }^{56}$

\section{Mechanism of neuropathic pain}

Overall the mechanisms that contribute to the development of pain in diabetes are poorly understood but probably involve deficits at multiple levels from the skin nociceptors to the pain processing areas of the brain. ${ }^{16}$ It is also important to 


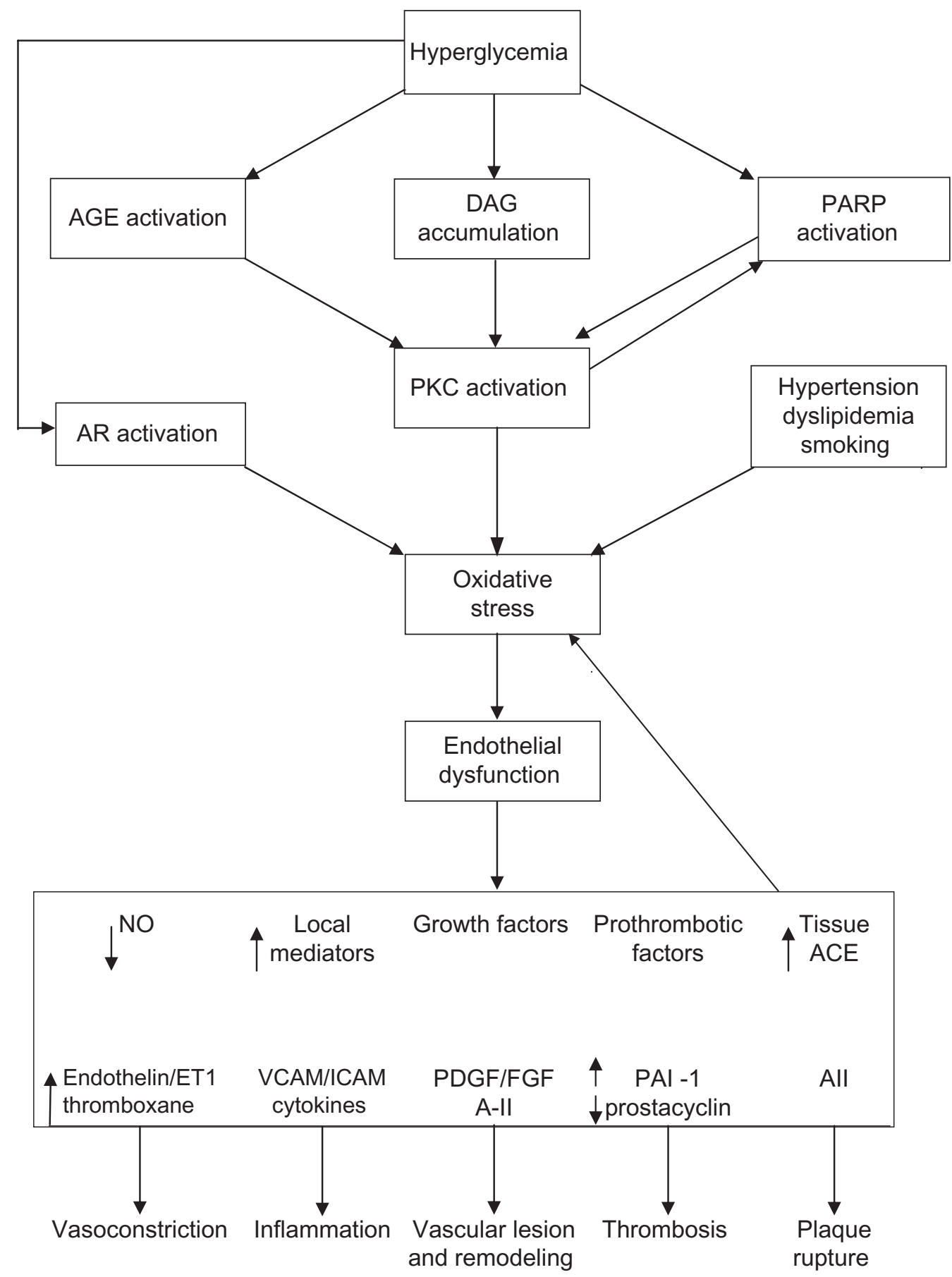

Figure 3 Pathophysiology of microvascular injury.

Abbreviations: ACE, angiotensin converting enzyme; AGE, glycation end products; AR, aldose reductase; DAG, diacylglycerol; PARP, poly (ADP ribose) polymerase; PKC, protein kinase C; VCAM, vascular cell adhesion molecules.

consider the impact of cultural influences on the perception of pain, since the experience of pain complicating diabetes differs across ethnic groups which cannot be explained on the basis of clinical findings. The pain pathway starts from the periphery with nociceptor activation and transmission through the small unmyelinated $\mathrm{C}$ fibers and the larger myelinated $A-\delta$ fibers and A- $\beta$ fibers. The major neurotransmitter in $C$ fibers is glutamate and its release is regulated through calcium channels. Glutamate in turn excites postsynaptic N-methylD-aspartate (NMDA) receptors resulting in the release of substance $\mathrm{P}$ in the substantia gelatinosa, an important neurotransmitter of pain perception. The descending fibers modulate the response to pain via serotonergic, opioidergic, and $\alpha$-2-adrenergic pathways. ${ }^{64}$ The A- $\beta$ the A- $\delta$ fibers 
transmit pain perception by depolarization, which is mediated by sodium channels, of which sodium channels 1.7 and 1.8 play an important role in pain signaling via glutamate. This excites an interneuron with release of $\gamma$-aminobutyric acid (GABA), which further modulates pain sensation. ${ }^{65,66}$ Interestingly, a number of studies suggest that loss of IENFs is related to the development of pain in a variety of chronic disease states. For example, subjects with painful diabetic neuropathy have been shown to exhibit a significant reduction of IENFD compared with diabetic patients with painless neuropathy. ${ }^{67}$

The definition of neuropathic pain (NP) as proposed by International Association of Study of Pain "pain initiated or caused by a primary lesion or dysfunction in the nervous system" has limitations as it overlooks the plasticity of the nervous system and its continuous modulation, which may change after activation or injury. ${ }^{68}$ The word "dysfunction" in the definition of NP allows the inclusion of organic pain states that do not have identifiable lesions of any part of the nervous system or an initiating neural injury. The revised definition proposed by Treede et al, based on consensus statement defines NP as "pain arising as a direct consequence of a lesion or disease affecting the somatosensory system". ${ }^{68}$ Peripheral NP and central NP refer to lesions/disease of the peripheral nervous system and central nervous system, respectively.

\section{Treatment of diabetic polyneuropathy}

Treatment of DPN can be viewed as approaches aimed at modifying the disease process or strategies aimed at the alleviation of symptoms. Often the primary aim is to protect the lower limbs from damage due to sensory loss or to relieve pain, thus improving physical well-being and reducing psychological distress in order to enhance the quality of life.

\section{Disease-modifying treatment Glycemic control}

The pathogenesis of DPN is fundamentally mediated by hyperglycemia and/or insulin deficiency and their associated downstream actions. Indeed, glycemic control appears to be the most effective treatment to slow the progression of diabetic neuropathy and delay its onset. In the DCCT, intensive metabolic control with insulin resulted in a $60 \%$ reduction in clinical and electrophysiological evidence of neuropathy compared to standard care over a period of 5 years in subjects with type 1 diabetes. ${ }^{69,70}$ In patients with early diabetes, intensive glycemic control significantly attenuates neuropathy progression. ${ }^{70}$ Furthermore, the beneficial effect of intensive glycemic control applied early in the course of diabetes appears to have long-lasting effects (metabolic memory) ${ }^{71}$ However, the DCCT gave little evidence that established neuropathy could be reversed by intensive insulin therapy. In the Epidemiology of Diabetes Intervention and Complication Trial (EDIC Trial), 64\% of the original cohort from DCCT were followed up for 16 years. The incidence of diabetic neuropathy remained lower in subjects previously randomized to intensive treatment after 5 years despite the lack of difference in $\mathrm{HbA}_{1 \mathrm{c}}$. The term "imprinting" of metabolic memory or "legacy" effect has been coined to describe this effect. ${ }^{71}$

Limited information exists with regards to the effects of glycemic control on pain. Boulton et al demonstrated that greater mean glucose excursions are associated with higher neuropathic pain scores and that use of continuous subcutaneous insulin infusion resulted in significant improvement in pain scores. These studies were, however, limited to a small number of patients. ${ }^{72,73}$

In the (UK Prospective Diabetes Study) UKPDS, in newly diagnosed type 2 diabetes, intensive treatment with sulfonylurea, metformin, and insulin, which resulted in a $0.9 \%$ reduction in $\mathrm{HbA}_{1 \mathrm{c}}$ after 10 years compared to conventional treatment, led to $25 \%$ reduction in microvascular endpoints, especially in retinopathy progression and albuminuria. ${ }^{74,75}$ However, absent ankle reflexes, taken as a sign of diabetic neuropathy were noted in $35 \%$ and $37 \%$ of intensively and conventionally treated subjects respectively, suggesting limited impact on this endpoint. In the Steno-2 trial, which assessed the efficacy of multifactorial risk factor intervention, improvements in glycemic control, lipid profile, and blood pressure were associated with a reduction in the odds ratio to 0.32 for the development of autonomic neuropathy. ${ }^{76}$ Intensification of metabolic control did not affect the progression of DPN, but may have reflected the limited assessment of DPN performed in this study (limited to a biothesiometer assessment).

\section{$\alpha$-lipoic acid}

As discussed above, there is considerable evidence for an important role for neurovascular dysfunction in the pathogenesis of DPN related to the downstream effects of free radical-mediated oxidative stress. D-L- $\alpha$-lipoic acid (ALA) is a potent antioxidant, which has been extensively evaluated in prospective, placebo-controlled studies in subjects with diabetic neuropathy. A meta-analysis of 1258 patients who were treated with infusions of ALA (600 mg intravenously/ day) concluded that neuropathic symptoms and deficit were reduced after 3 weeks of treatment. ${ }^{77,78}$ 
Initial studies with ALA showed limited benefit in symptom scores with some improvement in nerve electrophysiology. In the (Alpha-Lipoic Acid in Diabetic Neuropathy) ALADIN II trial, subjects with type 1 and type 2 diabetes complicated by symptomatic polyneuropathy were randomly assigned for 2 years to $1200 \mathrm{mg}$, or $600 \mathrm{mg}$ ALA or placebo after intravenous infusion of ALA or placebo. The severity of diabetic neuropathy was assessed by the neuropathy disability score and electrophysiological studies. No significant differences between the groups were detected after 24 months apart from dose-dependent improvement in electrophysiological nerve function. In the ALADIN III trial, there was a small but significant improvement in neuropathy impairment score in patients treated with ALA. ${ }^{79,80}$

However, in the Symptomatic Diabetic Neuropathy (SYDNEY) 1 trial, ALA intravenously given for 3 weeks was associated with improvement of symptoms. In SYDNEY 2 trial, three doses of oral ALA $(600,1200$, or $1800 \mathrm{mg}$ daily) or placebo were randomly assigned to 181 diabetes patients with symptomatic polyneuropathy for 5 weeks. All three doses were associated with significant improvement in the neuropathy total symptom score compared to placebo. ${ }^{81,82}$

The benefit and safety of ALA has been demonstrated in a long-term study, NATHAN, which was a multicenter, randomized, double-masked, parallel group clinical trial involving 460 diabetic patients with polyneuropathy randomly assigned to receive ALA $600 \mathrm{mg}$ or placebo. After 4 years, ALA was shown to be well tolerated and to improve neuropathic symptoms and deficits compared to a progression of these endpoints in the placebo arm. ${ }^{83}$ ALA has been licensed and is currently used in treatment of symptomatic diabetic neuropathy in Germany. A dose of $600 \mathrm{mg} /$ day appears to offer the best balance between efficacy and side effect profile.

\section{Protein kinase $\mathrm{C}$}

Activation of $\mathrm{PKC}$ is thought to be an important pathogenetic pathway in diabetic microvascular complications. In the multinational, randomized, Phase II double-blind placebocontrolled trial using ruboxistaurin (a PKC- $\beta$ inhibitor) there was, however, no difference in the primary endpoint of change in vibration detection threshold (VDT). For the secondary endpoint, there was improvement in the neuropathy total symptom score 6 (NTSS 6). Patients who had significant symptoms at baseline did show a statistically significant change in symptoms with $64 \mathrm{mg}$ dose but not with a $32 \mathrm{mg}$ dose compared to the placebo. In a subgroup analysis of patients with clinically significant symptoms and less severe DPN, there was significant greater reduction in NTSS 6 total score with the $64 \mathrm{mg}$ dose $(P=0.006$ vs placebo) and an improvement in the VDT. ${ }^{84,85}$

\section{Polyol pathway}

Aldose reductor inhibitors (ARIs) reduce the flux of glucose through the polyol or sorbitol pathway, resulting in the reduction of intracellular accumulation of sorbitol and fructose. In a 52-week, multicenter, placebo-controlled, double-blind trial, the use of fidarestat in patients with type 1 and type 2 diabetes with peripheral neuropathy was associated with significant improvement in five out of the eight electrophysiological measures over the course of the study with no deterioration from baseline in the treated group. At the study conclusion, the fidarestat-treated group improved significantly compared with the placebo group in two of the electrophysiological measures. There was also subjective symptomatic improvement in the treated group. ${ }^{86}$ The ARI epalrestat is approved in Japan for clinical use. The clinical efficacy has been assessed in a 3-year, open-label, randomized control trial (RCT) of 594 DPN subjects. One hundred and fifty $\mathrm{mg} /$ day of epalrestat was found to result in improvement in patients' symptoms and prevented the deterioration of median motor nerve conduction velocity and minimum $\mathrm{F}$ wave latency. ${ }^{87}$

Another ARI that has been evaluated in a Phase III study is ranirestat. 549 patients with DPN were randomized to placebo or 10,20 , or $40 \mathrm{mg} /$ day of ranirestat for 52 weeks. There was no change in the Toronto clinical neuropathy score and quantitative sensory testing among the groups. There were nonsignificant changes in sural and sensory nerve conduction but significant improvement in summed motor nerve conduction velocity of tibial, peroneal, and median nerves in the ranirestat group by 12 weeks. ${ }^{88}$ Currently, the focus has changed from reversing established disease to slowing the progression of neuropathy and a prospective clinical trial with ranirestat is underway to address this.

\section{Advanced glycation end products}

The accumulation of AGEs and activation of AGE receptors results in multiple downstream pathogenetic effects leading to microvascular damage. However the identification and testing of a safe AGE inhibitor has proved problematic. The inhibition of AGE formation, amino-guanidine, was discontinued because of toxicity in humans. ${ }^{89}$

Benfotiamine, a derivative of thiamine (vitamin B1), has been shown to reduce tissue AGEs. Studies of benfotiamine in subjects with DPN with varying doses and duration have been reported to show some effectiveness compared to placebo. 
A 6-week, placebo-controlled study with benfotiamine $300 \mathrm{mg}$ or $600 \mathrm{mg}$ demonstrated a reduction in neuropathic symptoms, which was optimal at the higher dose. Benfotiamine has also been studied in combination with pyridoxamine (vitamin B6) and cyanocobalamin (vitamin B12). These studies reported a significant improvement in vibration perception threshold, motor function, and symptom score..$^{90,91}$

\section{Growth factors}

There is evidence for deficient neurotrophism in diabetes. However prospective clinical trials utilizing nerve growth factor (NGF) and neurotropin 3 did not show promising results. ${ }^{92,93}$ Another growth factor, vascular endothelial growth factor (VEGF), which is an important stimulus for angiogenesis, has been studied in animal models of diabetic neuropathy as well as in clinical trials in patients with diabetes. ${ }^{94,95}$ VEGF was shown to improve symptoms without effecting nerve electrophysiology. ${ }^{94}$ Islet neogenesis associated protein, a pancreatic cytokine that can regenerate the islet tissue when administered to diabetic mice, resulted in improvement in thermal hypoalgesia in the rodent model following 2 weeks of treatment. ${ }^{96}$

\section{Inhibition of PARP}

Chemical inhibition of PARP offers potential to slow or reverse diabetes complications including DPN. ${ }^{63}$ Weak PARP inhibitors such as nicotinamide can prevent experimental neuropathy in diabetic rodents. ${ }^{97}$ The challenge remains to develop more potent inhibitors that can be evaluated in patients.

\section{Angiotensin converting enzyme inhibitors}

The role of angiotensin converting enzyme inhibitors in DPN is probably due to inhibition of angiotensin II, which is a potent vasoconstrictor with pro-inflammatory properties, which especially in the absence of NO, promotes thrombosis and stimulation of vascular smooth muscle cells and adhesion molecules such as VCAM and intercellular adhesion molecules. The efficacy of trandolapril has been studied in 41 normotensive DPN patients who were randomly assigned to active treatment or placebo. Patients on trandolapril showed a small but significant improvement in several measures of peroneal and sural nerve physiology after 12 months of treatment compared with placebo. Vibration-perception threshold, autonomic function, and the neuropathy symptom and deficit score, however, showed no improvement in either group. ${ }^{98}$

\section{Symptomatic treatment}

Therapeutic targets to alleviate pain include diabetes-induced peripheral and central sensitization (Figures 5 and 6). There is no predictor of the response to analgesics dependent on the character of the pain, although some believe that burning pain responds best to antidepressants and shooting pain to anticonvulsants. These agents are widely used in clinical practice, although not all are supported by adequate prospective RCTs. It is of great importance to consider individual patient comorbidities and drug side-effect profile as many agents have dose-related and potentially serious side effects (Table 2).

\section{Tricyclic antidepressants}

Tricyclic antidepressants (TCAs) inhibit the reuptake of norepinephrine and/or serotonin. These agents may act by altering the central perception of pain or may antagonize the NMDA receptors in the dorsal horn that mediates hyperalgesia and allodynia. ${ }^{99}$ In a placebo-controlled, double-blind, randomized, cross-over trial comparing amitriptyline, desipramine, and fluoxetine with placebo, the average effective dose, titrated over 6 weeks to achieve control of symptoms, was $111 \mathrm{mg}$ /day for desipramine, $105 \mathrm{mg}$ /day for amitriptyline, and $40 \mathrm{mg}$ /day for fluoxetine. Both TCAs were equally effective and superior to fluoxetine or placebo. The beneficial effect was seen within 2 weeks and continued to increase at 6 weeks. The clinical response and tolerability of side effects are the best guides to dose titration, as there was no correlation demonstrated with pain relief, dosage, or plasma concentration. ${ }^{99,100}$ TCAs can cause prolongation of the QT interval and are contraindicated in patients with recent unstable angina, myocardial infarction, heart failure, history of ventricular arrhythmias, and significant disease of conduction pathway. ${ }^{101}$ Concern exists about

Table 2 Oral therapy for diabetic painful neuropathy

\begin{tabular}{llll}
\hline Drug class & Drug & $\begin{array}{l}\text { Daily dose } \\
(\mathbf{m g})\end{array}$ & NNT \\
\hline Tricyclics & Amitriptyline & $25-150$ & $2.4(2.0-3.0)$ \\
& Imipramine & $25-150$ & $2.4(2.0-3.0)$ \\
SSRIs & Paroxetine & 40 & $6.8(3.4-44 \mid)$ \\
& Citalopram & 40 & $6.8(3.4-44 I)$ \\
Anticonvulsants & Gabapentin & $900-1800$ & $3.7(2.4-8.3)$ \\
& Pregabalin & $150-600$ & $3.3(2.3-5.9)$ \\
& Carbamazepine & $200-400$ & $3.3(2.0-9.4)$ \\
& Topiramate & Up to 400 & $3.0(2.3-4.5)$ \\
Opioids & Tramadol & $50-400$ & $3.4(2.3-6.4)$ \\
& Oxycodone & $10-120$ & 2.6 \\
& & & $(1.19-4.1)$ \\
SNRIs & Venlaflaxine & $150-200$ & 5.5 \\
& & & $(3.4-4.14)$ \\
& Duloxetine & $60-120$ & $4.0(3-9)$ \\
\hline
\end{tabular}

Abbreviations: NNT, number needed to treat; SNRIs, selective serotonin norepinephrine reuptake inhibitors; SSRIs, selective serotonin reuptake inhibitors. 
their safety, particularly in patients with cardiovascular autonomic neuropathy.

\section{Selective serotonin reuptake inhibitors}

Selective serotonin reuptake inhibitors (SSRIs) inhibit presynaptic reuptake of serotonin but not norepinephrine and lack postsynaptic receptor blocking effects. These agents can be considered in patients who cannot tolerate TCAs. However, they should be used with caution, especially with aspirin and nonsteroidal anti-inflammatory drugs (NSAIDs), as a case-control study showed moderately increased risk of upper gastrointestinal bleeding. ${ }^{99}$

In a randomized, double-blind, crossover study, paroxetine $40 \mathrm{mg}$ /day significantly reduced neuropathic symptoms compared to placebo but was less effective than imipramine. ${ }^{102}$ Paroxetine was also shown to be effective in relieving both steady and lancinating type of pain and the therapeutic effect was seen within 1 week. The number needed to treat (NNT) to achieve $>50 \%$ pain relief was $6.8(3.4-441)$ and was not significant. Citalopram but not fluoxetine has been reported to have beneficial effects on pain relief. ${ }^{99,103}$

\section{Selective serotonin norepinephrine reuptake inhibitors}

Selective serotonin norepinephrine reuptake inhibitors (SNRIs) such as duloxetine and venlafaxine have been shown to be effective in relieving neuropathic pain by increasing the synaptic availability of 5-HT and norepinephrine in the descending pathways that inhibit pain impulses. The efficacy and safety has been established in three 12-week randomized, blinded, controlled trials involving 1102 subjects. Duloxetine, $60 \mathrm{mg}$ or $120 \mathrm{mg}$ daily, effectively reduced pain intensity ( $47 \%$ and $48 \%$ vs $29 \%$ with placebo). ${ }^{103-110}$ Duloxetine has a rapid onset of action with a reduction in pain scores within 24 hours with effects persisting for the duration of the study. It was effective at relieving pain at night. The medication was, in general, well-tolerated with only $20 \%$ discontinuation due to side effects. The most common side effects were nausea, somnolence, dizziness, decreased appetite, and constipation. Duloxetine is not associated with weight gain but may cause a slight increase in fasting blood glucose..$^{90}$ Duloxetine is licensed for treatment of neuropathy at a dose of $60 \mathrm{mg} /$ day. ${ }^{109}$

The efficacy of venlaflaxine extended release has been assessed in a 6-week multicenter, double-blind RCT involving 244 patients with DPN. Venlaflaxine was associated with significant benefit in the primary outcome measures of pain intensity and pain relief compared to placebo.
The most significant improvement in pain score occurred with higher dose of venlaflaxine, $50 \%$ on $150-225 \mathrm{mg}$, and $32 \%$ on $75 \mathrm{mg}$ vs $27 \%$ on placebo. The effect was attributed to a neuropathic rather than an antidepressant action since patients with depression were excluded. Nausea, somnolence, and myalgia were common side effects. Some patients on venlaflaxine had significant cardiac rhythm abnormalities. ${ }^{111}$

\section{Anticonvulsants}

Anticonvulsants have traditionally been utilized for the treatment of painful diabetic neuropathy. Older anticonvulsants such as carbamazepine are still useful in treating neuropathic pain but have been replaced by newer agents such as gabapentin and pregabalin, which have better efficacy and safety profile. ${ }^{112,113}$

Gabapentin is structurally related to aminobutyric acid, a neurotransmitter, involved in modulation of pain signals. Gabapentin binds to $\alpha 2-\delta$ subunit of voltage-activated calcium channels on the presynaptic neurone and reduces neurotransmitter release. ${ }^{112,113}$ In three randomized, double-blind studies, gabapentin was shown not only to improve painful neuropathy but also has an additional benefit of improving sleep. ${ }^{114-116}$ In an 8-week multicenter dose escalation trial, $60 \%$ of patients treated with gabapentin had moderate pain relief compared to $33 \%$ on placebo. Of the 165 patients, $67 \%$ achieved doses up to $3600 \mathrm{mg}$ per day, $23 \%$ of these patients experienced adverse events particularly dizziness and somnolence. A randomized study comparing gabapentin and amitriptyline did not show any difference in efficacy between the two drugs. ${ }^{115}$

Pregabalin is structurally related to gabapentin and has a six-fold higher binding affinity for $\alpha 2-\delta$ subunit of voltage-activated calcium channels but has no action on GABA or benzodiazepine receptors. ${ }^{117}$ It inhibits the release of excitatory neurotransmitters including glutamate, substance P, and CGRP. ${ }^{118,119}$ In a pooled analysis of seven randomized clinical trials of 5-13 weeks duration involving a total of 1510 patients, pregabalin at varying doses (150, $300,600 \mathrm{mg}$ ) demonstrated a significant reduction in mean pain score. There was better efficacy with higher doses but these were associated with increased incidence of side effects. Adverse effects included giddiness, tremors, dry mouth, and peripheral edema. Pregabalin-treated subjects demonstrated greater weight gain but this did not affect diabetes control. The conventional starting dose of pregabalin is $75 \mathrm{mg}$ twice daily but this can be slowly titrated to $300 \mathrm{mg}$ in divided doses over 1 week or more. ${ }^{120,121}$ 


\section{Sodium channel blockers}

Carbamazepine has been traditionally used for neuropathic pain and the use is limited by its side effects (dizziness, nausea, skin rash, and rare cases of leucopenia) and limited efficacy data. Studies have shown lamotrigine can attenuate the pain of DPN but the data on topiramate is equivocal. ${ }^{122-126}$

Lacosamide is an antiepileptic drug used as adjunctive therapy for partial-onset seizures. Studies suggest that lacosamide selectively enhances slow inactivation of voltage-gated sodium channels and unlike other anticonvulsants it does not influence fast sodium channel inactivation. The mechanism of action includes interaction with collapsin response mediator protein 2 , which plays an important role in regulating microtubule assembly in neurons. ${ }^{99}$ Lacosamide has been evaluated in a number of studies and in an 18-week, Phase III, doubleblind RCT, lacosamide in doses of 200, 400, $600 \mathrm{mg}$ was effective at pain relief in DPN. Similarly, in another Phase III trial of $400 \mathrm{mg} /$ day of lacosamide there was an improvement in Likert pain score compared to placebo. Most frequent adverse events are headache, nausea, and vertigo. ${ }^{127-129}$

\section{Topical applications Topical capsaicin cream}

Capsaicin is a naturally occurring pungent substance in red peppers and causes analgesia through local tissue depletion of substance $\mathrm{P}$, which is considered to be the primary neurotransmitter of painful stimuli from the periphery to the central nervous system. In randomized, double-blind placebocontrolled trials in patients with DPN; capsaicin cream has been associated with statistically significant improvement in symptoms and quality of life. Pooled data analysis of six trials involving 656 patients, showed that the relative benefit of topical capsaicin (0.075\%) compared with placebo was $1.4(95 \%$ CI: $1.2-1.7)$ and NNT was $5.7(4.0-10.0) .{ }^{130} \mathrm{It}$ is recommended that the duration of treatment should not be more than 8 weeks, although there were no detectable adverse effects on sensory function in diabetic patients. However, a study in healthy subjects showed $74 \%$ decrease in epidermal nerve fibers as early as 3 days, which may be a mechanism of analgesia, thus raising caution for its use in insensitive diabetic foot. ${ }^{131}$

\section{Topical lidocaine}

In an open-label trial, the use of 5\% lidocaine patches, (up to four patches for 18 hours/per day) significantly improved pain and quality of life score in 56 subjects with painful DPN. ${ }^{132}$ In another open-label study of 204 patients with DPN, the noninferiority of $5 \%$ lidocaine patch compared to pregabalin was evaluated. Pain response rate was comparable between the two treatment groups and lidocaine showed greater improvements in quality of life and had fewer side effects. ${ }^{132-134}$ Lidocaine patches are often utilized in concert with other analgesic agents.

\section{Opioids}

Opioid receptors are distributed throughout the nervous system and are involved in pain transmission and control, including primary afferent neurons, spinal cord, midbrain, and thalamus. Opioids produce effects on neurons by interacting with receptors located on neuronal cell membranes. The action of opioids at the presynaptic nerve terminal is to prevent neurotransmitter release and they exhibit inhibitory effects at the postsynaptic neuron. Tramadol acts directly via opioid receptors and may have an effect on postsynaptic neurons apart from acting indirectly via monoaminergic receptor systems. The efficacy of tramadol has been studied in a 6-week multicenter trial, which included 131 patients with painful DPN. There was $44 \%$ pain relief in the tramadol treated group compared to $12 \%$ on placebo. Common side effects are nausea and constipation. ${ }^{135}$ Stronger opioids such as controlled release oxycodone in doses of 10 to $60 \mathrm{mg}$ appear to be effective and safe in the treatment of DPN based on data from two randomized clinical trials. Opioids are a useful adjuvant to the treatment of painful DPN along with antidepressants. ${ }^{136,137}$

\section{Other agents}

Several other approaches have been evaluated to relieve pain in DPN.

\section{Topical agents}

Among the topical agents, isosorbide nitrate spray has shown promising results in a placebo-controlled pilot study of 22

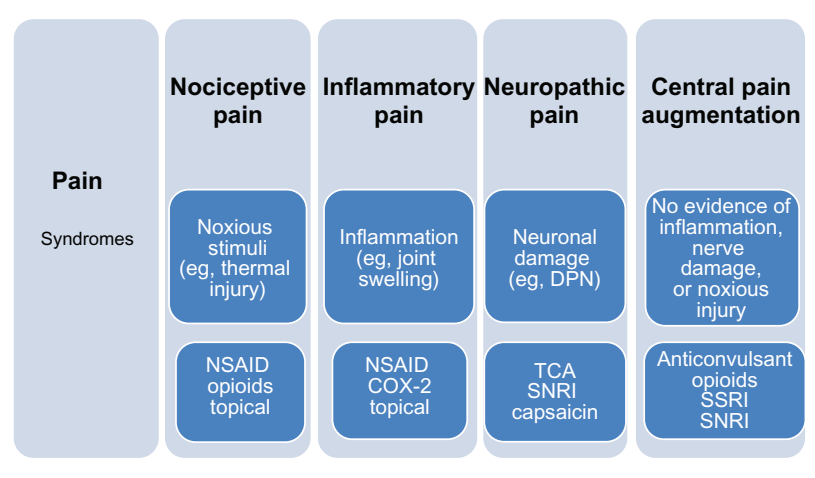

Figure 4 Clinical pain syndromes.

Abbreviations: DPN, diabetic polyneuropathy; SNRI, serotonin noradrenaline reuptake inhibitor; SSRIs, selective serotonin ruptake inhibitors; TCA, tricyclic antidepressant; NSAID, nonsteroidal anti-inflammatory drugs. 


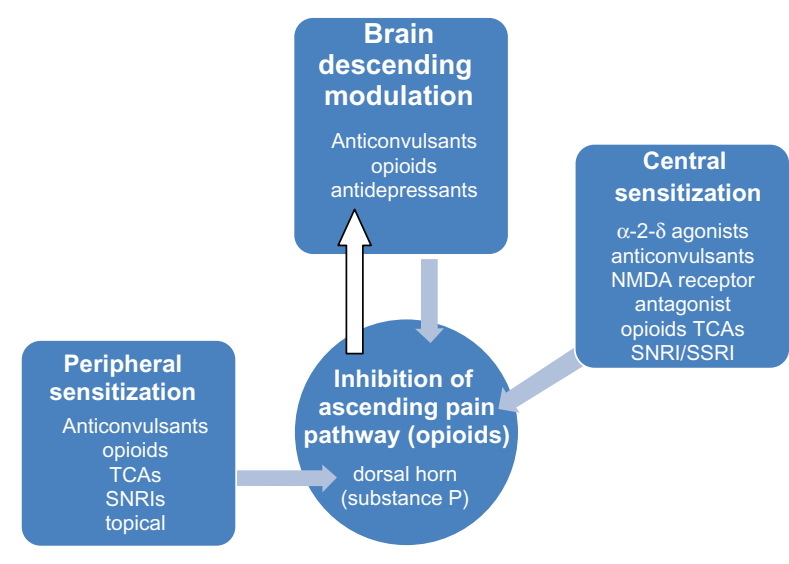

Figure 5 Pharmacotherapy of pain pathway.

Abbreviations: SNRI, serotonin noradrenaline reuptake inhibitor; SSRIs, selective serotonin reuptake inhibitors; TCA, tricyclic antidepressant.

DPN patients, which elicited a reduction in overall neuropathic pain and burning sensation. ${ }^{138}$ Similar results were also obtained by the use of glyceryl trinitrate patches in 18 patients with DPN with $44 \%$ reporting a reduction in pain. ${ }^{139}$

The combination of $4 \%$ amitriptyline and $2 \%$ ketamine (EpiCept NP-1) is being evaluated in Phase IIB study.
A borderline significant reduction in pain intensity has been demonstrated. ${ }^{140}$ Topical clonidine $(0.1 \%$ gel $)$ has been evaluated in a Phase II, double-blind RCT in 166 subjects with DPN. A 30\% reduction in pain was achieved in $47.2 \%$ of study subjects using the gel compound compared to $29.3 \%$ on placebo. ${ }^{140}$

\section{Taurine}

Taurine is an antioxidant with effects on neuronal calcium signaling which resembles pregabalin in diabetic rodent models. ${ }^{141}$ Taurine treatment has been shown to improve nerve blood flow and electrophysiological parameters and exhibit analgesic properties. A Phase II clinical trial utilizing a dose of $3 \mathrm{~g}$ /day in subjects with DPN is ongoing.

\section{Acetyl-L-carnitine}

Acetyl-L-carnitine (ALC), the acetylated ester of the amino acid L-carnitine, has been studied in patients with DPN. ALC therapy has been associated with significant improvement in pain scores in one of the two identically designed randomized, placebo-controlled trials in patients with DPN

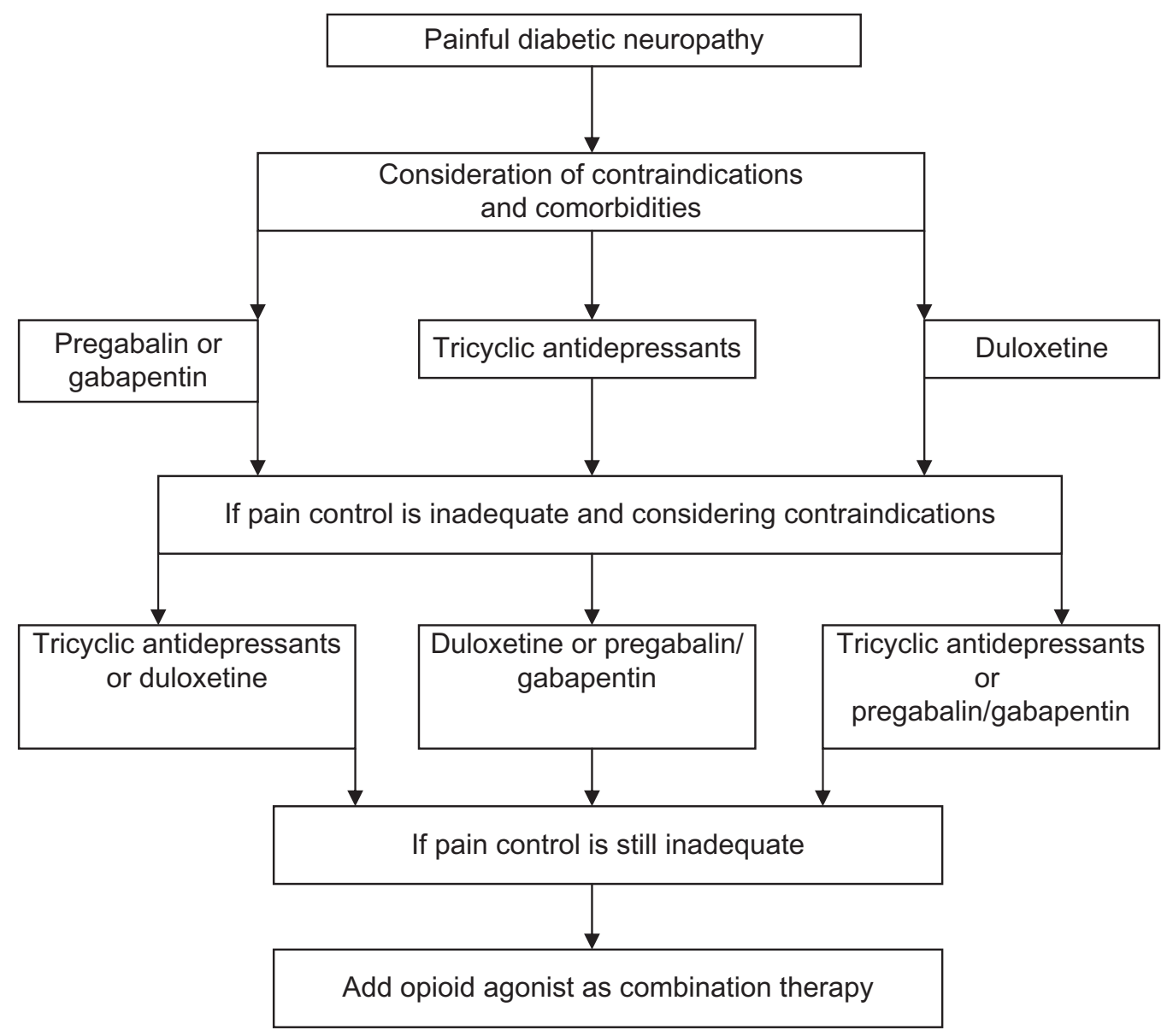

Figure 6 Treatment algorithm for painful diabetic polyneuropathy. 
Table 3 Newer agents for diabetic peripheral neuropathy

\begin{tabular}{|c|c|c|c|}
\hline Compound & Indication & Stage of development & MOA \\
\hline \multirow[t]{4}{*}{ Tectin } & $\mathrm{DN}$ & Preclinical & Sodium channel antagonist \\
\hline & Post-op pain & & \\
\hline & Post-herpetic & & \\
\hline & Cancer related pain & & \\
\hline \multirow[t]{2}{*}{ Amitriptyline + ketamine } & $\mathrm{DN}$ & Phase II & TCA, SNRI, NMDA antagonist \\
\hline & Post-herpetic & & \\
\hline Clonidine, topical & $\mathrm{DN}$ & Phase II & Alpha 2 adrenoreceptor agonist \\
\hline Coleneuramide & $\mathrm{DN}$ & Phase II & NGF modulator \\
\hline \multirow[t]{2}{*}{ Indantadol } & $\mathrm{DN}$ & Phase II & NMDA antagonist and MAO inhibitor \\
\hline & Post-op pain & & \\
\hline Radiprodil & $\mathrm{DN}$ & Phase II & NMDA 2B receptor antagonist \\
\hline \multirow[t]{2}{*}{ SB-509 } & $\mathrm{DN}$ & Phase II & Gene therapy VEGF \\
\hline & PVD & & \\
\hline Acetyl L- carnitine & $\mathrm{DN}$ & Phase III & Antioxidant and affects $\mathrm{Na} / \mathrm{K}$ ATPase, NO, PGN \\
\hline Fidarestat & $\mathrm{DN}$ & Phase III & AR inhibitor \\
\hline \multirow[t]{3}{*}{ Lacosamide } & $\mathrm{DN}$ & Phase III & Enhances the inactivation of slow voltage- \\
\hline & Epilepsy & & dependent NA channels. \\
\hline & Fibromyalgia & & \\
\hline Memantine $\mathrm{HCL}$ & $\mathrm{DN}$ & Phase III & NMDA antagonist \\
\hline \multirow[t]{3}{*}{ Nabiximols } & $\mathrm{DN}$ & Phase III & Cannabinoid receptor I agonist \\
\hline & MS & & \\
\hline & Cancer pain & & \\
\hline Ranirestat & $\mathrm{DN}$ & Phase III & AR inhibitor \\
\hline \multirow[t]{3}{*}{ Ruoxistaurin mesylate } & $\mathrm{DN}$ & Phase III & PKC inhibitor \\
\hline & DR & & \\
\hline & DNeph & & \\
\hline \multirow[t]{2}{*}{ Tapentadol, ER } & $\mathrm{DN}$ & Phase III & Dual mu-opioid receptor agonist and \\
\hline & Post-op pain & & norepinephrine reuptake inhibitor \\
\hline
\end{tabular}

Abbreviations: $A R$, aldose reductase; DN, diabetic neuropathy; DR, diabetic retinopathy; DNeph, diabetic nephropathy; MAO, mono amine oxidase; MOA, mechanism of action; MS, multiple sclerosis; NGF, nerve growth factor; NMDA, N-methyl-D-aspartate; NO, nitric oxide; PGN, prostaglandin; PKC, protein kinase C; PVD, peripheral vascular disease; SNRI, serotonin noradrenaline reuptake inhibitor; TCA, tricyclic antidepressant; VEGF, vascular endothelial growth factor.

at doses of $1000 \mathrm{mg}$ three times daily. This benefit needs to be confirmed in future studies. ${ }^{142,143}$

\section{Nonsteroidal anti-inflammatories}

NSAIDs may be effective in DPN patients with underlying musculoskeletal or joint abnormalities by modulating the nociceptive and inflammatory pain pathways. Ibuprofen at a dose of $600 \mathrm{mg}$ four times daily and sulindac at a dose of $200 \mathrm{mg}$ twice daily can provide pain relief in DPN. ${ }^{144}$

Failure to respond to pharmacological agents may require referral to a pain clinic at which specialized techniques such as transcutaneous electrical nerve stimulation (TENS), percutaneous electrical nerve stimulation, or spinal cord electrostimulation should be considered.

\section{Management of focal neuropathies}

Few systematic studies have addressed the optimal approach to the management of most focal neuropathies. Diabetic amyotrophic may benefit from use of steroid and immunoglobulins. There are also anecdotal reports of insulin being beneficial. ${ }^{43-45}$ The management for foot drop secondary to peroneal nerve damage is supportive including splints. Surgical decompression can be of value in median nerve entrapment and has been utilized in other compression focal neuropathies. ${ }^{145}$

\section{Treatment algorithm based on present evidence}

The first-line treatments based on clinical trial evidence are an SNRI, an $\alpha-2-\delta$ agonist, or TCA. Thus, duloxetine, pregabalin, or amitriptyline would be the drugs of choice as initial therapy after consideration of factors such as comorbidities and cost. Duloxetine is contraindicated in patients with liver disease and pregabalin should be avoided in those with edema. Cardiovascular disease or cardiac autonomic neuropathy (CAN) may preclude the use of amitriptyline. If pain control is not adequate, then a combination of first-line therapies could be considered before utilizing opioids ${ }^{16}$ (Figure 4).

\section{Conclusions}

DPN remains a common and disabling complication of diabetes. The initial treatment of DPN should focus upon the 
identification of risk factors and intensification of metabolic control, the implementation of a diabetic foot care program in subjects with insensitivity, and the provision of adequate pain or symptom relief to improve quality of life. In some patients, negative symptoms (ie, numbness or loss of function) are as disabling as positive symptoms such as pain and are perhaps more challenging to treat. Patient education is the key and pathophysiology of the disease should be explained and a treatment plan agreed upon. The psychological consequences of DPN should be sought and treatment offered. Symptoms that interfere with sleep are particularly disabling. Therapeutic strategies should be individualized taking into consideration underlying patient comorbidities. It is also important not to ignore multifactorial risk interventions such as weight reduction and smoking cessation along with blood pressure and lipid control. Improving patient mobility and the instigation of exercise regimens can be helpful in reducing symptoms. Newer techniques such as magnetic resonance imaging, IENFD, and corneal confocal microscopy are offering new insights into the pathogenesis of pain and small sensory fiber damage in DPN and directing the development of therapeutic agents (Table 3). Despite the relative lack of success of interventional agents to slow or reverse established DPN, approaches such as gene therapy to promote neurotrophism and the targeted delivery of antioxidant therapy may in the future offer the best potential to reverse this common and disabling complication of diabetes.

\section{Disclosure}

No conflicts of interest were declared in relation to this paper.

\section{References}

1. Vinik AI, Mitchell BD, Leichter SB, Wagner AL, O’Brian JT, Georges LP. Epidemiology of the complications of diabetes. In: Diabetes: Clinical Science in Practice. Leslie RDG, Robbins DC, editors. Cambridge, UK: Cambridge University Press;1995:221-287.

2. American Diabetes Association. American Academy of Neurology: Report and recommendations of the San Antonio conference on diabetic neuropathy. Diabetes Care. 1988;11:592-597.

3. Toeller M, Buyken AE, Heitkamp G, et al. Prevalence of chronic complications, metabolic control and nutritional intake in type 1 diabetes: comparison between different European regions. EURODIAB Complications Study group. Horm Metab Res. 1999;31:680-685.

4. Pirart J. Diabetes mellitus and its degenerative complication: a prospective study of 4,400 patients observed between 1947 and 1973. Diabetes Care. 1978;1:168-188.

5. Young MJ, Boulton AJ, MacLeod AF, Williams DR, Sonksen PH. A multicentre study of the prevalence of diabetic peripheral neuropathy in the United Kingdom hospital clinic population. Diabetologia. 1993;36:150-154.

6. Lehtinen JM, Niskanen L, Hyvonen K, Siitonen O, Uusitupa M. Nerve function and its determinants in patients with newly-diagnosed type 2 (non-insulin dependent) diabetes mellitus and in control subjects - a 5-year follow-up. Diabetologia. 1993;36:68-72.
7. Sumner CJ, Sheth S, Griffin JW, Cornblath DR, Polydefkis M. The spectrum of neuropathy in diabetes and impaired glucose tolerance. Neurology. 2003;60:108-111.

8. Ziegler D, Rathmann W, Dickhaus T, Meisinger C, Mielck A; KORA Study Group. Neuropathic pain in diabetes, prediabetes and normal glucose tolerance. The MONICA/KORA Augsburg Surveys S2 and S3. Pain Med. 2009;10:393-400.

9. Partanen J, Niskanen L, Lehtinen J, et al. Natural history of peripheral neuropathy in patients with non-insulin-dependent diabetes mellitus. N Engl J Med. 1995;333:89-94.

10. Ziegler D, Gries FA, Spuler M, Lessmann F. The epidemiology of diabetic neuropathy. Diabetic Cardiovascular Autonomic Neuropathy Multicenter Study Group. J Diabetes Comp. 1992;6:49-57.

11. Tesfaye S, Chaturvedi N, Eaton SE, et al; EURODIAB Prospective Complications Study Group. Vascular risk factors and diabetic neuropathy. $N$ Engl J Med. 2005;352:341-350.

12. Ziegler D, Rathmann W, Dickhaus T, Meisinger C, MielckA; for the KORA Study Group. Prevalence of polyneuropathy in prediabetes and diabetes is associated with abdominal obesity and macroangiopathy. MONICA/ KORA Augsburg Surveys S2 and S3. Diabetes Care. 2008; 31:464-469.

13. Thomas PK. Classification, differential diagnosis and staging of diabetic peripheral neuropathy. Diabetes. 1997;46(Suppl 2):S54-S57.

14. Thomas PK. Classification of the diabetic neuropathies. In: Gries FA, Cameron NE, Low PA, Ziegler D, editors. Textbook of Diabetic Neuropathy. Stuttgart, Germany: Thieme;2003:175-177.

15. Boulton AJM, Malik RA, Arezzo JC, Sosenko JM. Diabetic somatic neuropathies. Diabetes Care. 2004;27:1458-1486.

16. Boulton AJ, Vinik AI, Arezzo JC, et al. Diabetic neuropathies: a statement by the American Diabetes Association. Diabetes Care. 2005; 28:956-962.

17. Tesfaye S, Boulton AJ, Dyck PJ, et al. Diabetic neuropathies: update on definitions, diagnostic criteria, estimation of severity, and treatments. Diabetes Care. 2010;33:2285-2293.

18. Galer BS, Gianas A, Jensen MP. Painful diabetic neuropathy: epidemiology, pain description, and quality of life. Diabetes Res Clin Pract. 2000;47:123-128.

19. Sinnreich M, Taylor BV, Dyck PJ. Diabetic neuropathies. Classification, clinical features, and pathophysiological basis. Neurologist. 2005; 11:63-79.

20. Vinik A, Ullal J, Parson HK, Casellini CM. Diabetic neuropathies: clinical manifestations and current treatment options. Nat Clin Pract Endocrinol Metab. 2006;2:269-281.

21. Cavanagh PR, Simoneau GG, Ulbrecht JS. Ulceration, unsteadiness, and uncertainty: the biomechanical consequences of diabetes mellitus. J Biomech. 1993;26(Suppl 1):23-40.

22. Katoulis EC, Ebdon-Parry M, Lanshammar H, Vileikyte L, Kulkarni J, Boulton AJ. Gait abnormalities in diabetic neuropathy. Diabetes Care. 1997;20:1904-1907.

23. Archer AG, Watkins PJ, Thomas PK, Sharma AK, Payan J. The natural history of acute painful neuropathy in diabetes mellitus. J Neurol Neurosurg Psychiatry. 1983;46:491-499.

24. Tesfaye S, Chaturvedi N, Eaton SE, et al. Vascular risk factors and diabetic neuropathy. $N$ Engl J Med. 2005;352:341-350.

25. Steele JM, Young RJ, Lloyd GG, Clarke BF. Clinically apparent eating disorders in young diabetic women: associations with painful neuropathy and other complications. BMJ. 1987;294:859-866.

26. Dabby R, Sadeh M, Lampl Y, Gilad R, Watemberg N. Acute painful neuropathy induced by rapid correction of serum glucose levels in diabetic patients. Biomed Pharmacother. 2009;63:707-709.

27. Gemignani F. Acute painful diabetic neuropathy induced by strict glycemic control ("insulin neuritis"): the old enigma is still unsolved. Biomed Pharm. 2009;63:249-250.

28. Gorson KC, Herrmann DN, Thiagarajan R, et al. Non-length dependent small fibre neuropathy/ganglionopathy. J Neurol Neurosurg Psych. 2008;79:163-169.

29. Stevens MJ, Pop-Busui R, Holmes C. Can I prevent problems in the at risk diabetic foot? In: Clinical Challenges in Diabetes. Barnett A, editor. Oxford, UK: Clinical Publishing Services. 2008. 
30. Tentolouris N, Marinou K, Kokotis P, Karanti A, Diakoumopoulou E, Katsilambros N. Sudomotor dysfunction is associated with foot ulceration in diabetes. Diabet Med. 2009;26:302-305.

31. Liatis S, Marinou K, Tentolouris N, Pagoni S, Katsilambros N. Usefulness of a new indicator test for the diagnosis of peripheral and autonomic neuropathy in patients with diabetes mellitus. Diabet Med. 2007;24:1375-1380.

32. McArthur JC, Stocks EA, Hauer P, Cornblath DR, Griffin JW. Epidermal nerve fiber density: normative reference range and diagnostic efficiency. Arch Neurol. 1998;55:1513-1520.

33. Goransson LG, Mellgren SI, Lindal S, Omdal R. The effect of age and gender on epidermal nerve fiber density. Neurology. 2004;62:774-777.

34. Quattrini C, Tavakoli M, Jeziorska M, et al. Surrogate markers of small fiber damage in human diabetic neuropathy. Diabetes. 2007; $56: 2148-2154$.

35. Kennedy WR, Wendelschafer-Crabb G, Johnson T. Quantitation of epidermal nerves in diabetic neuropathy. Neurology. 1996;47:1042-1048.

36. Herrmann DN, Griffin JW, Hauer P, Cornblath DR, McArthur JC. Epidermal nerve fiber density and sural nerve morphometry in peripheral neuropathies. Neurology. 1999;53:1634-1640.

37. Shun CT, Chang YC, Wu HP, et al. Skin denervation in type 2 diabetes: correlations with diabetic duration and functional impairments. Brain 2004;127:1593-1605.

38. Pittenger GL, Ray M, Burcus NI, McNulty P, Basta B, Vinik AI. Intraepidermal nerves are indicators of small-fiber neuropathy in both diabetic and nondiabetic patients. Diabetes Care. 2004;27:1974-1979.

39. Mehra S, Tavakoli M, Kallinikos PA, et al. Corneal confocal microscopy detects early nerve regeneration after pancreas transplantation in patients with type 1 diabetes. Diabetes Care. 2007;30:2608-2612.

40. Dyck PJB, Norell JE, Dyck PJ. Microvasculitis and ischemia in diabetic lumbosacral radiculoplexus neuropathy. Neurology. 1999; 53:2113-2121.

41. Llewelyn JG, Thomas PK, King RHM. Epineurial microvasculitis in proximal diabetic neuropathy. J Neurol. 1998;245:159-165.

42. Kelkar PM, Masood M, Parry GJ. Distinctive pathologic findings in proximal diabetic neuropathy (diabetic amyotrophy). Neurology. 2000; 55:83-88.

43. Vinik A, Mehrabyan A, Colen L, Boulton A. Focal entrapment neuropathies in diabetes. Diabetes Care. 2004;27:1783-1788.

44. Garland H. Diabetic amyotrophy. Br J Clin Pract. 1961;15:9-13.

45. Asbury AK. Proximal diabetic neuropathy. Ann Neurol. 1977;2: 179-180.

46. Chokroverty S, Reyes MG, Rubino FA, et al. The syndrome of diabetic amyotrophy. Ann Neurol. 1977;2:131.

47. Brownlee M. Biochemistry and molecular cell biology of diabetic complications. Nature. 2001;414:813-820.

48. Singh R, Barden A, Mori T, Beilin L. Advanced glycation end products: a review. Diabetologia. 2001;44:129-146.

49. Friedman EA. Advanced glycosylated end products and hyperglycemia in the pathogenesis of diabetic complications. Diabetes Care. 1999;22(Suppl 2):B65-B71.

50. Charonis AS, Reger LA, Dege JE, et al. Laminin alterations after in vitro nonenzymatic glycosylation. Diabetes. 1990;39:807-814.

51. Abordo EA, Thornalley PJ. Synthesis and secretion of tumour necrosis factor-alpha by human monocytic THP-1 cells and chemotaxis induced by human serum albumin derivatives modified with methylglyoxal and glucose-derived advanced glycation endproducts. Immunol Lett. 1997;58:139-147.

52. Kirstein M, Aston C, Hintz R, Vlassara H. Receptor-specific induction of insulin-like growth factor $\mathrm{I}$ in human monocytes by advanced glycosylation end product-modified proteins. J Clin Invest. 1992;90(2):439-446.

53. Schmidt AM, Hori O, Chen JX, et al. Advanced glycation endproducts interacting with their endothelial receptor induce expression of vascular cell adhesion molecule-1 (VCAM-1) in cultured human endothelial cells and in mice. A potential mechanism for the accelerated vasculopathy of diabetes. J Clin Invest. 1995;96:1395-1403.
54. Brownlee M. The pathobiology of diabetic complications. Diabetes. 2005;54:1615-1625.

55. King GL, Brownlee M. The cellular and molecular mechanisms of diabetic complications. Endocrinol Metab Clin North Am. 1996; $25: 255-270$

56. Meier M, King GL. Protein kinase $C$ activation and its pharmacological inhibition in vascular disease. Vasc Med. 2000;5:173-185.

57. Figueroa-Romero C, Sadidi M, Feldman EL. Mechanisms of disease: the oxidative stress theory of diabetic neuropathy. Rev End Metab Dis. 2008;9:301-314.

58. Baynes JW, Thorpe SR. Role of oxidative stress in diabetic complications: a new perspective on an old paradigm. Diabetes. 1999; 48:1-9.

59. Nishikawa T, Kukidome D, Sonoda K, et al. Impact of mitochondrial ROS production on diabetic vascular complications. Diabetes Res Clin Pract. 2007;77(3 Suppl 1):S41-S45.

60. Bucala R, Tracey KJ, Cerami A. Advance glycation products quench nitric oxide and mediate endohelium dependent vasodilatation in experimental diabetes. J Clin Invest. 1991;87:432-438.

61. Hawthorne GC, Bartlett K, Hetherington CS, Albertic KG. The effects of high glucose on polyol pathway activity in cultured human endothelial cells. Diabetologia. 1989:32;196-199.

62. Wolf BA, Willianson JR, Easan RA, et al. Diacylglycerol accumulation and microvascular abnormalities induced by elevated blood glucose levels. J Clin Invest. 1991:87;31-38.

63. Vinik AI, Erbas T, Park TS, Stansberry KB, Scanelli JA, Pittenger GL. Dermal neurovascular dysfunction in type 2 diabetes. Diabetes Care. 2001;24:1468-1475

64. Obrosova IG, Drel VR, Pacher P, et al. Oxidative-nitrosative stress and poly(ADP-ribose) polymerase (PARP) activation in experimental diabetic neuropathy. Diabetes. 2005;54:3435-3441.

65. Baron R. Mechanisms of disease: neuropathic pain - a clincal perspective. Nature Clin Pract Neurol. 2006;2:95-106.

66. Lai J, Hunter JC, Porreca F. The role of voltage-gated sodium channels in neuropathic pain. Curr Opin Neurobiol. 2003;13:291-297.

67. Wood JN, Boorman JP, Okuse K, Baker MD. Voltage-gated sodium channels and pain pathways. J Neurobiol. 2004;61:55-71.

68. Loeser JD. CRPS: Current Diagnosis and Therapy, Progress in Pain Research and Management. Introduction by JD Loeser, Seattle, IASP Press. In Wilson PR, Stanton-Hicks M, Harden RN (editors) 2005;32:3-7.

69. Sorensen L, Molyneaux L, Yue DK. The relationship among pain, sensory loss, and small nerve fibers in diabetes. Diabetes Care. 2006; 29:883-887.

70. Treede RD, Jensen TS, Campbell JN, et al. Redefinition of neuropathic pain and a grading system for clinical use: consensus statement on clinical and research diagnostic criteria. Neurology. 2008; 70:1630-1635.

71. DCCT Research Group. The effect of intensive treatment of diabetes on the development and progression of long-term complications in insulin dependent diabetes mellitus. N Engl J Med. 1993;329:977-986.

72. DCCT Research Group. The effect of intensive diabetes therapy on the development and progression of neuropathy. Ann Intern Med. 1995; 122:561-568.

73. Albers JW, Herman WH, Pop-Busui R, et al. Effect of prior intensive insulin treatment during the diabetes control and complications trial (DCCT) on peripheral neuropathy in type 1 diabetes during the epidemiology of diabetes interventions and complications (EDIC) study. Diabetes Care. 2010;33:1090-1096.

74. Oyibo SO, Prasad YD, Jackson NJ, Jude EB, Boulton AJ. The relationship between blood glucose excursions and painful diabetic peripheral neuropathy: a pilot study. Diabet Med. 2002;19:870-873.

75. Boulton AJ, Drury J, Clarke B, Ward JD. Continuous subcutaneous insulin infusion in the management of painful diabetic neuropathy. Diabetes Care. 1982;5:386-390.

76. UK Prospective Diabetes Study Group. Tight blood pressure control and risk of macrovascular and microvascular complications in type 2 diabetes: UKPDS 38. BMJ. 1998;317:703-713. Erratum in BMJ 1999;318(7175):29. 
77. UK Prospective Diabetes Study (UKPDS) Group. Effect of intensive blood-glucose control with metformin on complications in overweight patients with type 2 diabetes (UKPDS 34). Lancet. 1998;352:854-865.

78. Gaede P, Vedel P, Larsen N, Jensen G, Parving H, Pedersen O. Multifactorial intervention and cardiovascular disease in patients with type 2 diabetes. $N$ Engl J Med. 2003;384:383-393.

79. Ruhnau KJ, Meissner HP, Finn R, et al. Effects of 3-week oral treatment with the antioxidant thioctic acid (alpha-lipoic acid) in symptomatic diabetic polyneuropathy. Diabet Med. 1999;16:1040-1043.

80. Ziegler D, Nowak H, Kempler P, Vargha P, Low PA. Treatment of symptomatic diabetic polyneuropathy with the antioxidant alpha-lipoic acid: a meta-analysis. Diabet Med. 2004;21:114-121.

81. Ziegler D, Hanefeld M, Ruhnau KJ, et al. Treatment of symptomatic diabetic peripheral neuropathy with the anti-oxidant alpha-lipoic acid. A 3-week multicentre randomized controlled trial (ALADIN Study). Diabetologia. 1995;38:1425-1433.

82. Reljanovic M, Reichel G, Rett K, et al. Treatment of diabetic polyneuropathy with the antioxidant thioctic acid (alpha-lipoic acid): a two year multicenter randomized double-blind placebo-controlled trial (ALADIN II). Alpha Lipoic Acid in Diabetic Neuropathy. Free Radic Res. 1999;31:171-179.

83. Ametov AS, Barinov A, Dyck PJ, et al. The sensory symptoms of diabetic polyneuropathy are improved with alpha-lipoic acid: the SYDNEY trial. Diabetes Care. 2003;26:770-776.

84. Ziegler D, Ametov A, Barinov A, et al. Oral treatment with alpha-lipoic acid improves symptomatic diabetic polyneuropathy: the SYDNEY 2 trial. Diabetes Care. 2006;29:2365-2370.

85. Ziegler D, Low PA, Boulton AJ, et al. Effect of 4-year antioxidant treatment with alpha-lipoic acid in diabetic polyneuropathy: The NATHAN 1 Trial [abstract]. Diabetes. 2007;56:A2.

86. Vinik A, Bril V, Kempler P, et al; MBBQ Study. Treatment of symptomatic diabetic peripheral neuropathy with protein kinase $\mathrm{CB}$ inhibitor ruboxistaurin mesylate during a 1-year randomized, placebo-controlled, double-blind clinical trial. Clin Ther. 2005;27:1164-1180s.

87. Vinik AI, Bril V, Litchy WJ, Price KL, Bastyr EJ III. Sural sensory action potential identifies diabetic peripheral neuropathy responders to therapy. Muscle Nerve. 2005;32:619-625.

88. Hotta N, Toyota T, Matsuoka K, et al. Clinical efficacy of fidarestat, a novel aldose reductase inhibitor, for diabetic peripheral neuropathy. Diabetes Care. 2001;24:1776-1782.

89. Hotta N, Shigeta Y, Sakamoto N. Long-term effects of epalrestat, an aldose reductase inhibitor, on diabetic peripheral neuropathy: a 3-y multicenter comparative study, ARI-Diabetes Complications Trial (ADCT) [abstract]. Diabetes. 2005;54:A213.

90. Bril V, Hirose T, Tomioka S, Buchanan R. Ranirestat for the management of diabetic sensorimotor polyneuropathy. Diabetes Care. 2009;32:1256-1260.

91. Miyauchi Y, Shikama H, Takasu T, et al. Slowing of peripheral motor nerve conduction was ameliorated by aminoguanidine in streptozocininduced diabetic rats. Eur J Endocrinol. 1996;134:467-473.

92. Haupt E, Ledermann H, Kopcke W. Benfotiamine in the treatment of diabetic polyneuropathy - a three-week randomized, controlled pilot study (BEDIP study). Int J Clin Pharmacol Ther. 2005;43:71-77.

93. Stracke H, Lindemann A, Federlin K. A benfotiamine-vitamin B combination in treatment of diabetic polyneuropathy. Exp Clin Endocrinol Diabetes. 1996;104:311-316.

94. Pittenger G, Vinik A. Nerve growth factor and diabetic neuropathy. Exp Diabesity Res. 2003;4:271-285.

95. Vinik A. Treatment of diabetic polyneuropathy (DPN) with recombinant human nerve growth factor (rhNGF) [abstract]. Diabetes. 1999;48[Suppl 1]:A54-A55.

96. Chattopadhyay M, Krisky D, Wolfe D, Glorioso JC, Mata M, Fink DJ. HSV-mediated gene transfer of vascular endothelial growth factor to dorsal root ganglia prevents diabetic neuropathy. Gene Therapy. $2005 ; 12: 1377-1384$.
97. Ropper AH, Gorson KC, Gooch CL, et al. Vascular endothelial growth factor gene transfer for diabetic polyneuropathy: a randomized, doubleblinded trial. Ann Neurol. 2009;65:386-393.

98. Tam J, Rosenberg L, Maysinger D. INGAP peptide improves nerve function and enhances regeneration in streptozotocin-induced diabetic C57BL/6 mice. FASEB J. 2004;18:1767-1769.

99. Stevens MJ, Li F, Drel VR, et al. Nicotinamide reverses neurological and neurovascular deficits in streptozotocin-diabetic rats. $J$ Pharm Exp Ther. 2007;320:458-464.

100. Malik RA, Williamson S, Abbott C, et al. Effect of angiotensinconverting-enzyme (ACE) inhibitor trandolapril on human diabetic neuropathy: randomised double-blind controlled trial. Lancet. 1998;352:19.

101. Ziegler D. Painful diabetic neuropathy. Diabetes Care. 2009; 32(Suppl 2):S414-S419.

102. Max M, Lynch S, Muir J. Effects of desipramine, amitryptiline and fluoxetine on pain in diabetic neuropathy. $N$ Engl $J$ Med. 1992;326:1250-1256.

103. Ray WA, Meredith S, Thapa PB, et al. Cyclic antidepressants and the risk of sudden cardiac death. Clin Pharmacol Ther. 2004;75:234-241.

104. Sindrup S, Gram L, Brosen K. The selective serotonin reuptake inhibitor paroxetine is effective in treatment of diabetic neuropathy symptoms. Pain. 1990;42:135-144.

105. Finnerup NB, Otto M, McQuay HJ, et al. Algorithm for neuropathic pain treatment: an evidence based proposal. Pain. 2005;118:289-305.

106. Tesfaye S, Selvarajah D. Recent advances in the pharmacological management of painful diabetic neuropathy. Br J Diabetes Vasc Dis. 2009;9:283-287.

107. Raskin J, Wang F, Pritchett YL, Goldstein DJ. Duloxetine for patients with diabetic peripheral neuropathic pain: a 6-month open-label safety study. Pain Med. 2006;7:373-385.

108. Goldstein DJ, Lu Y, Detke MJ, et al. Duloxetine vs placebo in patients with painful diabetic neuropathy. Pain. 2005;116:109-118.

109. Raskin J, Pritchett YL, Wang F, et al. A double-blind, randomized multicenter trial comparing duloxetine with placebo in the management of diabetic peripheral neuropathic pain. Pain Med. 2005;6:346-356.

110. Wernicke JF, Pritchett YL, D'Souza DN, et al. A randomized controlled trial of duloxetine in diabetic peripheral neuropathic pain. Neurology. 2006;67:1411-1420.

111. [No authors listed]. Duloxetine (Cymbalta) for diabetic neuropathic pain. Med Lett Drugs Ther. 2005;47:67.

112. Hardy T, Sachson R, Shen S, et al. Does treatment with duloxetine for neuropathic pain impact glycemic control? Diabetes Care. 2007;30:21-26.

113. Rowbotham MC, Goli V, Kunz NR, Lei D. Venlafaxine extended release in the treatment of painful diabetic neuropathy: a double-blind, placebo-controlled study. Pain. 2004;110:697-706.

114. Vinik A. Advances in diabetes for the millennium: new treatments for diabetic neuropathies. Med Gen Med. 2004;6(3 Suppl):13.

115. Vinik A. Use of antiepileptic drugs in the treatment of chronic painful diabetic neuropathy. J Clin Endocrinol Metab. 2005;90:4936-4945

116. Backonja M, Beydoun A, Edwards KR, et al. Gabapentin for the symptomatic treatment of painful neuropathy in patients with diabetes mellitus. A randomized controlled trial. JAMA. 1998;280:1831.

117. Morello CM, Leckband SG, Stoner CP, et al. Randomized double-blind study comparing the efficacy of gabapentin with amitriptyline on diabetic peripheral neuropathy pain. Arch Intern Med. 1999;159:1931.

118. Rowbotham M, Harden N, Stacey B, et al. Gabapentin for the treatment of postherpetic neuralgia: a randomized controlled trial. JAMA. 1998;280:1837-1842.

119. Bryans JS, Wustrow DJ. 3-substituted GABA analogs with central nervous system activity: a review. Med Res Rev. 1999;19:149-177.

120. Dooley DJ, Mieske CA, Borosky SA. Inhibition of K(+)-evoked glutamate release from rat neocortical and hippocampal slices by gabapentin. Neurosci Lett. 2000;280:107. 
121. Fehrenbacher JC, Taylor CP, Vasko MR. Pregabalin and gabapentin reduce release of substance $\mathrm{P}$ and CGRP from rat spinal tissues only after inflammation or activation of protein kinase C. Pain. 2003;105:133-141.

122. Freeman R, Durso-Decruz E, Emir B. Efficacy, safety, and tolerability of pregabalin treatment for painful diabetic peripheral neuropathy: findings from seven randomized, controlled trials across a range of doses. Diabetes Care. 2008;31:1448-1454.

123. Frampton JE, Scott LJ. Pregabalin: in the treatment of painful diabetic peripheral neuropathy. Drugs. 2004;64:2813-2820.

124. Eisenberg E, Lurie Y, Braker C, et al. Lamotrigine reduces painful diabetic neuropathy: a randomized, controlled study. Neurology. 2001;57:505-509.

125. Rull JA, Quibrera R, Gonzalez-Millan H, Lozano CO. Symptomatic treatment of peripheral diabetic neuropathy with carbamazepine (Tegretol): double blind crossover trial. Diabetologia. 1969;5:215-218.

126. McQuay H, Carroll D, Jadad AR, et al. Anticonvulsant drugs for management of pain: a systematic review. BMJ. 1995;311:1047-1052.

127. Raskin P, Donofrio PD, Rosenthal NR, et al. Topiramate vs placebo in painful diabetic neuropathy: analgesic and metabolic effects. Neurology. 2004;63:865-873.

128. Thienel U, Neto W, Schwabe SK, Vijapurkar U. Topiramate Diabetic Neuropathic Pain Study Group. Topiramate in painful diabetic polyneuropathy: findings from three double-blind placebo-controlled trials. Acta Neurol Scand. 2004;110:221-231.

129. Shaibani A, Fares S, Selam JL, et al. Lacosamide in painful diabetic neuropathy: an 18-week double-blind placebo-controlled trial. J Pain. 2009; 10:818-828.

130. Wymer JP, Simpson J, Sen D, Bongardt S. Efficacy and safety of lacosamide in diabetic neuropathic pain: an 18-week doubleblind placebo-controlled trial of fixed-doseregimens. Clin J Pain. 2009;25:376-385.

131. Ziegler D, Hidvegi T, Gurieva I, et al. Efficacy and safety of lacosamide in painful diabetic neuropathy. Diabetes Care. 2010;33:839-841.

132. Mason L, Moore RA, Derry S, Edwards JE, McQuay HJ. Systematic review of topical capsaicin for the treatment of chronic pain. BMJ. 2004;328:991.

133. Nolano M, Simone DA, Wendelschafer-Crabb G, Johnson T, Hazen E, Kennedy WR. Topical capsaicin in humans: parallel loss of epidermal nerve fibers and pain sensation. Pain. 1999;81:135-145.

134. Barbano RL, Herrmann DN, Hart-Gouleau S, et al. Effectiveness, tolerability, and impact on quality of life of the $5 \%$ lidocaine patch in diabetic polyneuropathy. Arch Neurol. 2004;61:914-918.
135. Baron R, Mayoral V, Leijon G, et al. 5\% lidocaine medicated plaster versus pregabalin in post-herpetic neuralgia and diabetic polyneuropathy: an open-label, non-inferiority two-stage RCT study. Curr Med Res Opin. 2009;25:1663-1676.

136. Baron R, Mayoral V, Leijon G, et al. 5\% lidocaine medicated plaster versus pregabalin in post-herpetic neuralgia and diabetic polyneuropathy: an open-label, non-inferiority two-stage RCT study. Curr Med Res Opin. 2009;25:1663-1676.

137. Harati Y, Gooch C, Swenson M, et al. Double-blind randomized trial of tramadol for the treatment of the pain of diabetic neuropathy. Neurology. 1998;50:1842-1846.

138. Watson CP, Moulin D, Watt-Watson J, et al. Controlled-release oxycodone relieves neuropathic pain: a randomized controlled trial in painful diabetic neuropathy. Pain. 2003;105:71-78.

139. Gimbel JS, Richards P, Portenoy RK. Controlled-release oxycodone for pain in diabetic neuropathy: a randomized controlled trial. Neurology. 2003;60:927-934.

140. Yuen KC, Baker NR, Rayman G. Treatment of chronic painful diabetic neuropathy with isosorbide dinitrate spray: a double-blind placebocontrolled cross-over study. Diabetes Care. 2002;25:1699-1704.

141. Rayman G, Baker NR, Krishnan ST. Glyceryl trinitrate patches as an alternative to isosorbide dinitrate spray in the treatment of chronic painful diabetic neuropathy. Diabetes Care. 2003;26:2697-2698.

142. Pharmaprojects; 2010. Pharma R\&D annual review 2010. Available at: www.pharmaprojects.com. Accessed 15 May 2011.

143. Li F, Abatan OI, Kim H, et al. Taurine reverses neurological and neurovascular deficits in Zucker diabetic fatty rats. Neurobiol Dis. 2006;22:669-676.

144. Quatraro A, Roca P, Donzella C, et al. Acetyl-L-carnitine for symptomatic diabetic neuropathy. Diabetologia. 1995;38:123.

145. Sima AA, Calvani M, Mehra M, Amato A. Acetyl-L-carnitine improves pain, nerve regeneration, and vibratory perception in patients with chronic diabetic neuropathy: an analysis of two randomized placebocontrolled trials. Diabetes Care. 2005;28:89-94

146. Cohen KL, Harris S. Efficacy and safety of nonsteroidal antiinflammatory drugs in the therapy of diabetic neuropathy. Arch Intern Med. 1987;147:1442-1444.

147. Dellon AL. Treatment of symptomatic diabetic neuropathy by surgical decompression of multiple peripheral nerves. Plast Reconstr Surg. 1992;89:689-692.

\section{Publish your work in this journal}

Diabetes, Metabolic Syndrome and Obesity: Targets and Therapy is an international, peer-reviewed open-access journal committed to the rapid publication of the latest laboratory and clinical findings in the fields of diabetes, metabolic syndrome and obesity research. Original research, review, case reports, hypothesis formation, expert opinion and commentaries are all considered for publication. The manuscript management system is completely online and includes a very quick and fair peer-review system, which is all easy to use. Visit http://www.dovepress.com/testimonials.php to read real quotes from published authors. 